\title{
Low-Dose Metronomic Chemotherapy in Metastatic Breast Cancer: A Retrospective Analysis of 40 Patients
}

\author{
M. Souto*, A. Shimada, C. Chaul, M. Abrahão, A. Katz \\ Hospital Sírio Libanês, São Paulo, Brazil \\ Email: *msouto_med@hotmail.com
}

Received 24 July 2015; accepted 2 July 2016; published 5 July 2016

Copyright (C) 2016 by authors and Scientific Research Publishing Inc. This work is licensed under the Creative Commons Attribution International License (CC BY). http://creativecommons.org/licenses/by/4.0/ cC) (i) Open Access

\section{Abstract}

Purpose: Low-dose metronomic chemotherapy is an emergent treatment schedule in which low doses of cytotoxic agents are given orally continuously, with no or short drug-free intervals. In general, it provides better tolerance, especially in patients who have been previously exposed to other oncologic treatments, with a favorable cost-effectiveness profile. It is well known that all these low-dose schedules have a favorable safety profile and may provide an adequate tumor control in patients with metastatic breast cancer. However, there are no data in literature reporting the patient's tolerance and response to subsequent lines of chemotherapy after receiving metronomic regimens. Methods: We retrospectively analyzed 40 patients with metastatic breast cancer treated with low doses of Cyclophosphamide and/or Methotrexate and/or Capecitabine in a single center from June 2009 to April 2014. The following data were collected: age, hormone and epidermal growth factor receptor 2 (HER-2) status, number of lines of chemotherapy prior to and after low-dose metronomic treatment, duration of metronomic treatment, toxicity reason for treatment discontinuation. Duration of low-dose metronomic chemotherapy was also correlated with the variables analyzed and treatment outcomes. Results: The median time on metronomic chemotherapy was 5.4 months. The most frequent drugs administered were cyclophosphamide, methotrexate and capecitabine alone. Asthenia, myelotoxicity, gastrintestinal symptoms and handfoot syndrome were the most commonly recorded treatment related toxicity. Twenty six (65\%) patients had the opportunity to receive a classic chemotherapy regimen following metronomic regimen interruption. Although patients who developed toxicity to low-dose metronom- ic chemotherapy remained less time ( $<6$ months) in subsequent chemotherapy, there was no sta- tistically significant difference among those who received more lines of chemotherapy. Discussion: This is the first report in the literature describing the efficacy of low-dose metronomic regimens and the tolerance to subsequent lines of treatments following a period of metronomic chemotherapy. Most of our patients were able to tolerate conventional chemotherapy regimens administered in full

\footnotetext{
Corresponding author.
} 
doses. Several patients received as many as three lines of additional chemotherapy for periods that exceeded 6 months of treatment, which suggests that the use of prolonged metronomic treatment does not affect a patient's ability to tolerate subsequent therapy.

\author{
Keywords
}

Low-Dose Metronomic Chemotherapy, Metastatic, Breast, Cancer

\title{
1. Introduction
}

Worldwide, breast cancer is the most common cancer and is the leading cause of cancer death among women. Although its incidence has increased over the last years, the treatment remains essentially palliative, and some patients now experience a longer survival due to better tumor control, as a consequence of a better understanding of the molecular basis of their malignancy, the incorporation of new active drugs and the increasing use of several sequential lines of therapy [1]. On the other hand, in order to provide our patients with the opportunity of receiving many treatment lines with sustained or improved quality of life, we must be able to develop better supportive measure strategies as well as less toxic treatments. Unfortunately, it's common for a patient to discontinue treatment not for disease progression, but rather as a consequence of unacceptable accumulated toxicity, and therefore, being able to come up with a regimen with a better safety profile is of the upmost importance in the setting of an incurable disease, where prolongation of life with optimal quality constitutes the major goal of therapy [2].

Historically, most cytotoxic treatment regimens have been developed to be used at its maximum tolerated dose (MTD), in order to achieve better tumor control. However, a growing body of evidence now supports the fact that some low-dose chemotherapy agents, being used in a protracted fashion might in fact also prove to be as effective as full dose chemotherapy [3].

Low-dose metronomic (LDM) chemotherapy is an emergent treatment schedule in which low doses of cytotoxic agents are given orally continuously, with no or short drug-free intervals. In general, it provides better tolerance, especially in patients who have been previously exposed to other oncologic treatments, with a favorable cost-effectiveness profile [4] [5].

In 2000, two articles reporting the first rationale of chemotherapy in low doses were published. Klement et al. reported a significant and sustained regression of neuroblastoma with the use of low dose of vinblastine and an antibody against the vascular endothelial grown factor receptor (VEGFR). Browder et al. showed that cyclophosphamide, delivered in an antiangiogenic schedule (170 mg/kg every six days), was effective in promoting tumor control even in the setting of previous drug resistance [6] [7].

It is well known that all these low-dose schedules have a favorable safety profile and may provide an adequate tumor control in patients with metastatic breast cancer (MBC) [8]. However, there are no data in literature reporting the patient's tolerance and response to subsequent lines of chemotherapy after receiving metronomic regimens.

\section{Methods}

We retrospectively analyzed 40 patients with MBC treated with low doses of Cyclophosphamide and/or Methotrexate and/or Capecitabine in a single center from June 2009 to April 2014.

The following data were collected: age, hormone and epidermal growth factor receptor 2 (HER-2) status, stage at diagnosis, number of lines of chemotherapy prior to and after low-dose metronomic treatment, duration of metronomic treatment, toxicity reason for treatment discontinuation (disease progression, unacceptable toxicity or death). Degree of toxicity was evaluated according to the Common Terminology Criteria for Adverse Events (CTCAE), version 4.0. Duration of LDM treatment was also correlated with the variables analyzed and treatment outcomes. Patients who were still being treated at the time of data collection had their last evaluation recorded as the end of treatment.

The chi-square test was performed to identify statistical significance (level of 0.05 or less) between metro- 
nomic chemotherapy and the variables analyzed as well as the final status of patient, and $95 \%$ confidence intervals were calculated.

Patients were excluded if there were missing data related to any information aforementioned. Patients who received concomitant LDM therapy with another chemotherapeutic agent were also excluded, except for use of monoclonal antibody and anti-HER2 therapy.

The study was conducted in accordance with local regulatory requirements and approved by the institutional review board.

\section{Results}

Twenty six (65\%) patients presented ductal carcinoma. Positive hormonal receptor accounted for $70 \%$ of tumors, while only $5 \%$ were HER-2 positive.

Patient characteristics are outlined in Table 1.

The median time on metronomic chemotherapy was 5.4 months (range from 0.3 to 42.6 months). The most frequent drugs administered were cyclophosphamide $50 \mathrm{mg}$ daily combined to methotrexate $2.5 \mathrm{mg}$ twice weekly (67.5\%); capecitabine was used at $1500 \mathrm{mg}$ /day in combination with cyclophosphamide in 10 patients $(25 \%)$. Three (7.5\%) patients were treated with capecitabine at $1500 \mathrm{mg} /$ day as single agent. Twenty eight $(70 \%)$ patients received metronomic chemotherapy as the 1 st, 2 nd or 3rd line of treatment, $10(25 \%)$ between the 4 th and 6th line and $2(5 \%)$ after 6 previous lines.

Progression of disease was the most common reason of treatment interruption, and accounted for $65 \%$ of all treatment discontinuations, while toxicity was the cause of treatment interruption in $5(12.5 \%)$ patients. Toxicity data is summarized in Table 2.

Among 24 (60\%) patients who experienced any toxicity, 13 (54\%) presented grade I adverse event, 9 (37.5\%) grade II and $3(12 \%)$ grade III. Asthenia, myelotoxicity, gastrintestinal symptoms and hand-foot syndrome were the most commonly recorded treatment related toxicity.

Twelve patients $(30 \%)$ were already dead at the time of analysis, $26(65 \%)$ were alive with disease and $2(5 \%)$ were alive with no evidence of disease. Eight $(20 \%)$ patients are still in treatment with a metronomic regimen and $26(65 \%)$ had the opportunity to go on to receive a classic chemotherapy regimen following LDM interruption (Figure 1).

Of those, only one patient was submitted to less than three subsequent lines. Among those patients, $24(60 \%)$ remained on LDM chemotherapy for 12 months, $5(12.5 \%)$ remained on treatment for a period that varied between 12 and 24 months, 1 (2.5\%) remained on LDM therapy for 24 to 36 months and $2(5 \%)$ for a period of 36 to 48 months (Figure 2).

Although patients who developed toxicity to LDM remained less time ( $<6$ months) in subsequent chemotherapy (Odds Ratio 2.33), there was no statistically significant difference among those who received more lines of chemotherapy (OR for 6 to 12 months: 0.66 ; OR for more than 12 months: $0.33 ; p=0.512$ ).

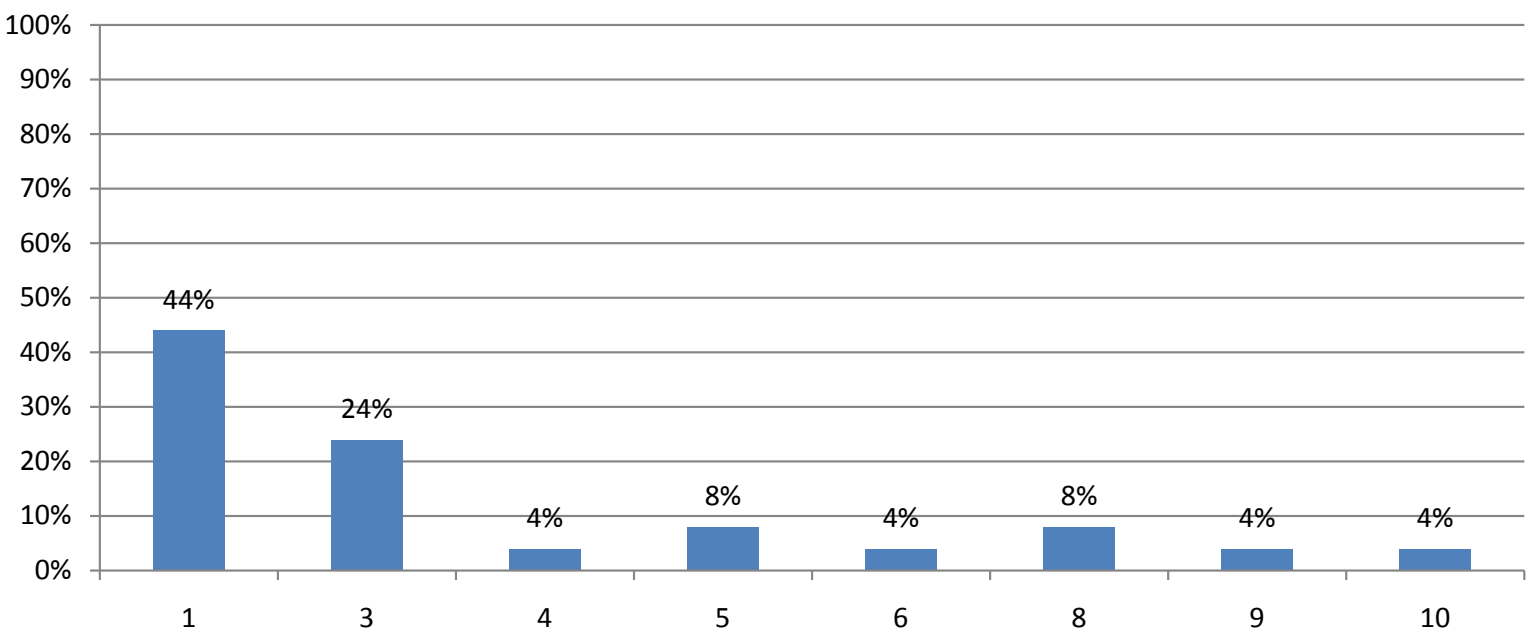

Figure 1. Lines of chemotherapy after metronomic regimens. 


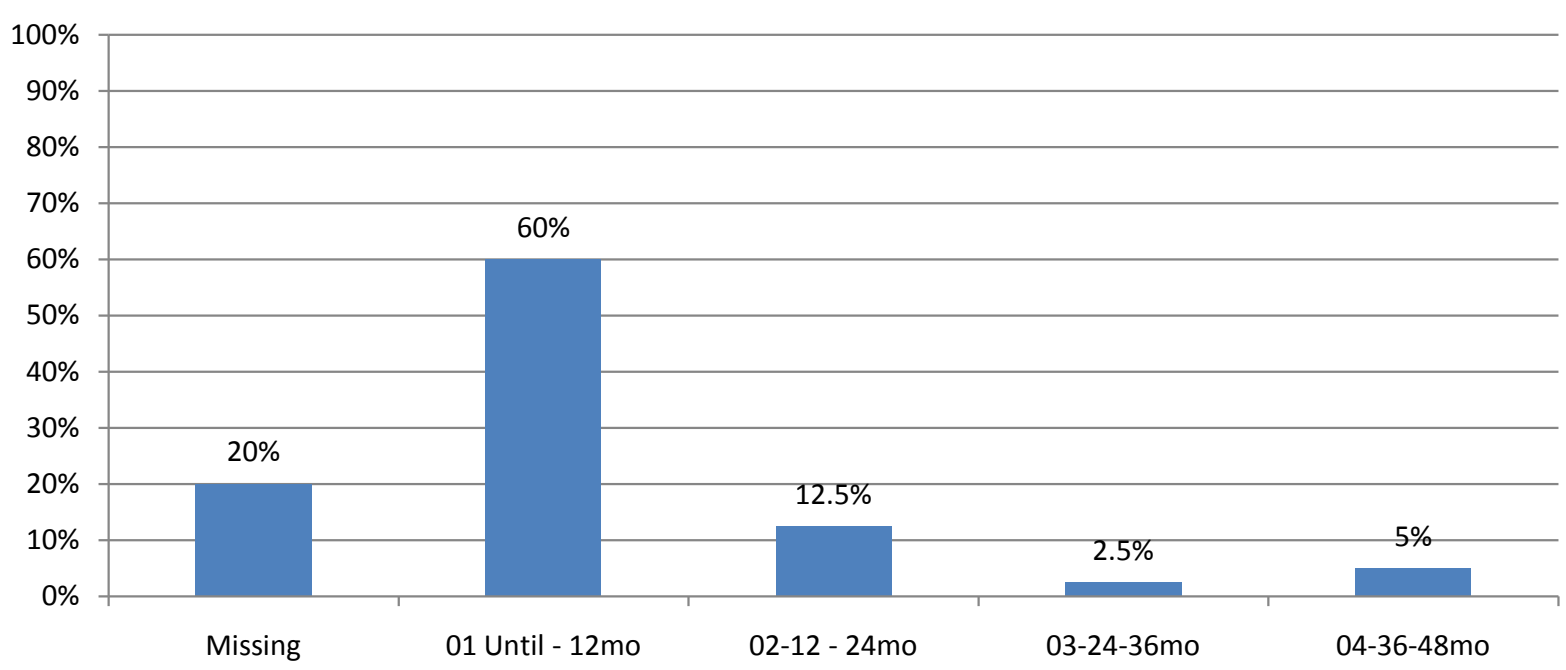

Figure 2. Timing in Metronomic QT.

Table 1. Patients characteristics.

\begin{tabular}{|c|c|c|}
\hline Age & & Years \\
\hline & Median & 52.5 \\
\hline & Range & $31-87$ \\
\hline \multirow[t]{3}{*}{ ER/PR } & & n (\%) \\
\hline & Positive & $28(70)$ \\
\hline & Negative & $12(30)$ \\
\hline \multicolumn{3}{|l|}{ HER-2 } \\
\hline & Positive & $5(12.5)$ \\
\hline & Negative & $35(87.5)$ \\
\hline \multicolumn{3}{|c|}{ Metronomic QT } \\
\hline & $\mathrm{CTX}+\mathrm{MTX}$ & $27(67.5)$ \\
\hline & CTX + Capecitabine & $10(25)$ \\
\hline & Capecitabine & $3(7.5)$ \\
\hline
\end{tabular}

Table 2. Adverse events.

\begin{tabular}{|cc|}
\hline Toxicity & n (\%) \\
\hline Yes & $24(60)$ \\
No & $16(40)$ \\
Asthenia & $5(20.8)$ \\
Mielotoxicity & $5(20.8)$ \\
Gastrintestinal & $4(16.6)$ \\
Symptoms & \\
Hand-Foot & $8(33.3)$ \\
Syndrome & \\
Grade & \\
I & $13(54)$ \\
II & $9(37.5)$ \\
III & $3(12)$ \\
\hline
\end{tabular}




\section{Discussions}

In the MBC setting, an improved survival has been noted over the last years and patients have increasingly been treated with a greater number of chemotherapy lines [1]. Most of regimens have been developed and are prescribed, at least initially, at their MTD. The treatment evolves frequent dose modifications and delays are often required and might eventually compromise the treatment's anti-tumor efficacy. On the other hand, there is a growing concern with treatment related toxicities and its potential for negatively affecting patient's quality of life [4].

Therefore, the development of treatment strategies that provide adequate long-term tumor control allied with minimal toxicity constitutes a major medical need. In addition, there is a worldwide growing concern with treatment costs, and as a consequence, the development of effective, well tolerated and affordable, cost-effective strategies becomes of global, paramount importance.

In addition, the use of conventional cytotoxic agents, such as cyclophosphamide in a metronomic regimen may provide additional access to alternative mechanisms of action, such as antiangiogenic properties, not usually manifested when the drug is given at its MTD in a conventional fashion [4].

Cyclophosphamide is the most widely drug used in a metronomic schedule, generally given in doses that vary between 10 and $25 \mathrm{~g} / \mathrm{kg}$, daily. It corresponds to $2 \%-6 \%$ of the standard dose [9]. Its antiangiogenic activity is one of mechanisms that inhibit the growth of tumor, potentially present when given alone or in combination with other agents, as methotrexate. Both drugs have demonstrated efficacy in the control of endothelial cell proliferation with documented decrease in serum VEGF levels [10].

Metronomic cyclophosphamide may target tumor angiogenesis by decreasing tumor endothelial cell proliferation and reducing the population of CD4+ CD25+ regulatory T cells that suppress antitumor immunity [11].

MTX could also have a pro-apoptotic effect at intermediate doses, as demonstrated when peripheral blood mononuclear cells were stimulated with Candida albicans and then exposed to MTX. In addition, there was an increased level of cleaved poly (ADP-ribose) polymerase (PARP) and a similar mechanism of action could be responsible to the activity of the drug when used in low doses in MBC, probably acting as a PARP inhibitor [12].

Capecitabine is an orally administered fluoropyrimidine that simulates continuous infusion of 5-fluorouracil. It is approved for MBC as single agent in dose of $2500 \mathrm{mg} / \mathrm{m}^{2} /$ day, however, it is generally associated with a poor tolerance. Thus, some studies have evaluated lower doses of this agent and some of them demonstrated improvement in tolerability without decreasing clinical benefit [13].

To our knowledge, this is the first report in the literature describing the efficacy of LDM and the tolerance to subsequent lines of treatments following a period of metronomic chemotherapy. Most of our patients were able to tolerate conventional chemotherapy regimens administered in full doses. Several patients received as many as three lines of additional chemotherapy for periods that exceeded 6 months of treatment, which suggested that the use of prolonged metronomic treatment did not affect a patient's ability to tolerate subsequent therapy.

Our results corroborate this hypothesis, since we have shown no relation between toxicity to LDM chemotherapy and tolerance to subsequent classic treatment regimens. The Odds Ratio were 2.33, 0.66 and 0.33 for respectively $<6$ months, between 6 and 12 months and $>12$ months, with no statistically significant difference (p $=0.512$ ) between these groups.

Even though HER-2 positive tumors represented a minority of sample and most of patients were hormonal receptor positive, and thus had a less aggressive disease that could allow more time in treatment, the good tolerance to metronomic chemotherapy may not be influenced by this bias.

Another point to be considered is that LDM chemotherapy was started early, since $70 \%$ of patients received this schedule in the first three lines of treatment. One potential explanation is that our sample has a different profile of patients, characterized by a more indolent disease that does not need an aggressive intervention upfront. Consequently, findings from this study may not be generalizable to routine clinical practice, and patients should be assessed individually.

The toxicity profile is in accordance with other papers reporting the use of LDM therapy. Asthenia, myelotoxicity, gastrintestinal symptoms and hand-foot syndrome were the most common side effects. High-grade toxicities were exceedingly uncommon. There were only three adverse events grade 3 (diarrhea and hand-foot syndrome), similar to what has been reported in a phase II study in which patients received metronomic cyclophosphamide and capecitabine after progressing to taxane and anthracycline based regimen [14] [15]. 
Recently, a retrospective study compared 86 patients receiving capecitabine $1.000 \mathrm{mg}$ twice daily for 14 days every 21 days with 12 prior trials in which capecitabine was delivered in higher doses. The clinical benefit rate and time to progression were similar between the regimens, but median overall survival was twofold higher in the low-dose group (24 months vs. $12.1 \mathrm{mo}$ ) [16].

Our study is limited by the fact that we are reporting a retrospective case series which could potentially have introduced a selection bias in the patients treated with LDM therapy. However, given the results reported here, in terms to efficacy, tolerance and the potential for its low cost, in an era of extremely expensive treatment options, we believe that larger, prospectively well designed and well conducted trial should further explore this treatment strategy, as well as compare it to conventional chemotherapeutic regimens. In the meantime, the practicing oncologist may consider this form of therapy as another potential useful form of therapy in the management of selected breast cancer patients. In conclusion, LDM chemotherapy provides a long-term treatment with a good safety profile for patients with $\mathrm{MBC}$ and this approach should be considered for all patients with small amount of disease, poor performance status or for those who could not tolerate potential side effects.

\section{References}

[1] Kesson, E.M., Allardice, G.M., George, W.D., Burns, H.J. and Morrison, D.S. (2012) Effects of Multidisciplinary Team Working on Breast Cancer Survival: Retrospective, Comparative, Interventional Cohort Study of 13722 Women. $B M J, 344$, e2718. http://dx.doi.org/10.1136/bmj.e2718

[2] Dafni, U., Grimani, I., Xyrafas, A., Eleftheraki, A.G. and Fountzilas, G. (2010) Fifteen-Year Trends in Metastatic Breast Cancer Survival in Greece. Breast Cancer Research and Treatment, 119, 621-631. http://dx.doi.org/10.1007/s10549-009-0630-8

[3] Hanahan, D., Bergers, G. and Bergsland, E. (2000) Less Is More, Regularly: Metronomic Dosing of Cytotoxic Drugs Can Target Tumor Angiogenesis in Mice. Journal of Clinical Investigation, 105, 1045-1047. http://dx.doi.org/10.1172/JCI9872

[4] Lien, K., Georgsdottir, S., Sivanathan, L., Chan, K. and Emmenegger, U. (2013) Low-Dose Metronomic Chemotherapy: A Systematic Literature Analysis. European Journal of Cancer, 49, 3387-3395. http://dx.doi.org/10.1016/j.ejca.2013.06.038

[5] Bocci, G., Tuccori, M., Emmenegger, U., Liguori, V., Falcone, A., Kerbel, R.S. and Del Tacca, M. (2005) Cyclophosphamide-Methotrexate "Metronomic" Chemotherapy for the Palliative Treatment of Metastatic Breast Cancer. A Comparative Pharmacoeconomic Evaluation. Annals of Oncology, 16, 1243-1252. http://dx.doi.org/10.1093/annonc/mdi240

[6] Klement, G., Baruchel, S., Rak, J., Man, S., Clark, K., Hicklin, D.J., Bohlen, P. and Kerbel, R.S. (2000) Continuous Low-Dose Therapy with Vinblastine and VEGF Receptor-2 Antibody Induces Sustained Tumor Regression without Overt Toxicity. Journal of Clinical Investigation, 105, R15-R24. http://dx.doi.org/10.1172/JCI8829

[7] Browder, T., Butterfield, C.E., Kräling, B.M., Shi, B., Marshall, B., O’Reilly, M.S. and Folkman, J. (2000) Antiangiogenic Scheduling of Chemotherapy Improves Efficacy against Experimental Drug-Resistant Cancer. Cancer Research, 60, 1878-1886.

[8] Montagna, E., Cancello, G., Dellapasqua, S., Munzone, E. and Colleoni, M. (2014) Metronomic Therapy and Breast Cancer: A Systematic Review. Cancer Treatment Reviews, pii: S0305-7372(14)00112-1.

[9] Penel, N., Adenis, A. and Bocci, G. (2012) Cyclophosphamide-Based Metronomic Chemotherapy: After 10 Years of Experience, Where Do We Stand and Where Are We Going? Critical Reviews in Oncology/Hematology, 82, 40-50. http://dx.doi.org/10.1016/j.critrevonc.2011.04.009

[10] Colleoni, M., Rocca, A., Sandri, M.T., Zorzino, L., Masci, G., Nolè, F., Peruzzotti, G., Robertson, C., Orlando, L., Cinieri, S., de, B.F., Viale, G. and Goldhirsch, A. (2002) Low-Dose Oral Methotrexate and Cyclophosphamide in Metastatic Breast Cancer: Antitumor Activity and Correlation with Vascular Endothelial Growth Factor Levels. Annals of Oncology, 13, 73-80. http://dx.doi.org/10.1093/annonc/mdf013

[11] Kummar, S., Ji, J., Morgan, R., Lenz, H.J., Puhalla, S.L., Belani, C.P., Gandara, D.R., Allen, D., Kiesel, B., Beumer, J.H., Newman, E.M., Rubinstein, L., Chen, A., Zhang, Y., Wang, L., Kinders, R.J., Parchment, R.E., Tomaszewski, J.E. and Doroshow, J.H. (2012) A Phase I Study of Veliparib in Combination with Metronomic Cyclophosphamide in Adults with Refractory Solid Tumors and Lymphomas. Clinical Cancer Research, 18, 1726-1734. http://dx.doi.org/10.1158/1078-0432.CCR-11-2821

[12] Nielsen, C.H., Albertsen, L., Bendtzen, K. and Baslund, B. (2007) Methotrexate Induces Poly(ADP-Ribose) Polymerase-Dependent, Caspase 3-Independent Apoptosis in Subsets of Proliferating CD4+ T Cells. Clinical \& Experimental Immunology, 148, 288-295. http://dx.doi.org/10.1111/j.1365-2249.2007.03335.X

[13] Rossi, D., Alessandroni, P., Catalano, V., Giordani, P., Fedeli, S.L., Fedeli, A., Baldelli, A.M., Casadei, V., Ceccolini, 
M. and Catalano, G. (2007) Safety Profile and Activity of Lower Capecitabine Dose in Patients with Metastatic Breast Cancer. Clinical Breast Cancer, 7, 857-860. http://dx.doi.org/10.3816/CBC.2007.n.050

[14] Pasquier, E., Kavallaris, M. and André, N. (2010) Metronomic Chemotherapy: New Rationale for New Directions. Nature Reviews Clinical Oncology, 7, 455-465. http://dx.doi.org/10.1038/nrclinonc.2010.82

[15] Wang, Z., Lu, J., Leaw, S., Hong, X., Wang, J., Shao, Z. and Hu, X. (2012) An All-Oral Combination of Metronomic Cyclophosphamide plus Capecitabine in Patients with Anthracycline- and Taxane-Pretreated Metastatic Breast Cancer: A Phase II Study. Cancer Chemotherapy and Pharmacology, 69, 515-522. http://dx.doi.org/10.1007/s00280-011-1728-3

[16] Ambros, T., Zeichner, S.B., Zaravinos, J., Montero, A.J., Ahn, E., Aruna, M., Kronish, L., Mahtani, R.L. and Vogel, C.L. (2014) A Retrospective Study Evaluating a Fixed Low Dose Capecitabine Monotherapy in Women with HER-2 Negative Metastatic Breast Cancer. Breast Cancer Research and Treatment, 146, 7-14.

http://dx.doi.org/10.1007/s10549-014-3003-x

\section{Submit or recommend next manuscript to SCIRP and we will provide best service for you:}

Accepting pre-submission inquiries through Email, Facebook, Linkedin, Twitter, etc A wide selection of journals (inclusive of 9 subjects, more than 200 journals)

Providing a 24-hour high-quality service

User-friendly online submission system

Fair and swift peer-review system

Efficient typesetting and proofreading procedure

Display of the result of downloads and visits, as well as the number of cited articles

Maximum dissemination of your research work

Submit your manuscript at: http://papersubmission.scirp.org/ 